ISSN: 2231-3354

Received on: 08-03-2012

Revised on: 17-03-2012

Accepted on: 24-03-2012

Sanjay Bajaj, Neha Sakhuja Swami Vivekanand College of Pharmacy, Banur, I ndi a,

\section{Dinesh Singla}

Panacea Biotec Ltd, Lalru, I ndia

\section{Stability Testing of Pharmaceutical Products}

\author{
Sanjay Bajaj, Dinesh Singla and Neha Sakhuja
}

\begin{abstract}
Stability studies ensuring the maintenance of product quality, safety and efficacy throughout the shelf life are considered as pre-requisite for the acceptance and approval of any pharmaceutical product. These studies are required to be conducted in a planned way following the guidelines issued by $\mathrm{ICH}$, WHO and or other agencies. Importance of various methods followed for stability testing of pharmaceutical products, guidelines issued for stability testing and other aspects related to stability of pharmaceutical products have been presented in a concise manner in the present review
\end{abstract}

Keywords: Stability, Stability studies, Stability testing

\section{INTRODUCTION}

Stability testing of pharmaceutical products is a complex set of procedures involving considerable cost, time consumption and scientific expertise in order to build in quality, efficacy and safety in a drug formulation. Scientific and commercial success of a pharmaceutical product can only be ensured with the understanding of the drug development process and the myriad tasks and milestones that are vital to a comprehensive development plan. The most important steps during the developmental stages include pharmaceutical analysis and stability studies that are required to determine and assure the identity, potency and purity of ingredients, as well as those of the formulated products (Singh et al., 2000). Stability of a pharmaceutical product may be defined as the capability of a particular formulation in a specific container/closure system to remain within its physical, chemical, microbiological, toxicological, protective and informational specifications (Kommanaboyina et al., 1999). In other words, it is the extent to which a product retains, within the specified limits, throughout its period of storage and use, the same properties and characteristics possessed at the time of its packaging. Stability testing thus evaluates the effect of environmental factors on the quality of the a drug substance or a formulated product which is utilized for prediction of its shelf life, determine proper storage conditions and suggest labeling instructions. Moreover, the data generated during the stability testing is an important requirement for regulatory approval of any drug or formulation (Singh et al., 2000).

\section{Dr. Sanjay Bajaj}

Principal,

Swami Vivekanand College of

Pharmacy, Sector 8, Banur, 147601,

Distt. Patiala, Panjab, India.

Phone 01762 507994,

M dile 9814412082 
Stability testing is termed as a complex process because of involvement of a variety of factors influencing the stability of a pharmaceutical product. These factors include stability of the active ingredient(s); interaction between active ingredients and excipients, manufacturing process followed, type of dosage form, container/closure system used for packaging and light, heat and moisture conditions encountered during shipment, storage and handling. In addition, degradation reactions like oxidation, reduction, hydrolysis or racemization, which can play vital role in stability of a pharmaceutical product, also depend on such conditions like concentration of reactants, $\mathrm{pH}$, radiation, catalysts etc., as well as the raw materials used and the length of time between manufacture and usage of the product. A pharmaceutical product may undergo change in appearance, consistency, content uniformity, clarity (solution), moisture contents, particle size and shape, $\mathrm{pH}$, package integrity thereby affecting its stability. Such physical changes may be because of impact, vibration, abrasion, and temperature fluctuations such as freezing, thawing or shearing etc. The chemical reactions like solvolysis, oxidation, reduction, racemization etc. that occur in the pharmaceutical products may lead to the formation of degradation product, loss of potency of active pharmaceutical ingredient (API), loss of excipient activity like antimicrobial preservative action and antioxidants etc. (Carstensen et al., 2000). Stability of a pharmaceutical product can also be affected because of microbiological changes like growth of microorganisms in non sterile products and changes in preservative efficacy (Matthews et al., 1999). Potential adverse effects of instability in pharmaceutical products have been given in Table 1.

Table 1: Potential Adverse Effects of Instability in Pharmaceutical Products.

\begin{tabular}{|c|c|c|c|}
\hline $\begin{array}{l}\text { Potential Adverse } \\
\text { Effect }\end{array}$ & Explanation/ Reason & Example & Stability Parameter Tested \\
\hline Loss of Active Ingredient & $\begin{array}{l}\text { Degradation of API in product resulting in } \\
\text { less than } 90 \% \text { drug as claimed on label - } \\
\text { unacceptable quality }\end{array}$ & Nitroglycerine tablets & $\begin{array}{l}\text { Time elapsed before the drug content no } \\
\text { longer exceeds } 90 \%\end{array}$ \\
\hline $\begin{array}{l}\text { Increase in concentration of } \\
\text { active Ingredient }\end{array}$ & $\begin{array}{l}\text { Loss of vehicle perfusion bags sometimes } \\
\text { allow solvent to escape and evaporate so } \\
\text { that the product within the bag shows an } \\
\text { increase in concentration. }\end{array}$ & Lidocaine gel, products in perfusion bags & Stability in final container \\
\hline Alteration in bioavailability & $\begin{array}{l}\text { Changes in rate and extent of absorption on } \\
\text { storage }\end{array}$ & --- & Dissolution/release studies \\
\hline Loss of content uniformity & Loss of contents as a function of time & Suspension & $\begin{array}{l}\text { Ease of re- dispersion or sedimentation } \\
\text { volume }\end{array}$ \\
\hline $\begin{array}{l}\text { Decline of microbiological } \\
\text { status }\end{array}$ & $\begin{array}{l}\text { Increase in number of viable } \\
\text { microorganisms already present in the } \\
\text { product. Contamination because of } \\
\text { compromised package integrity during } \\
\text { distribution/ storage }\end{array}$ & Multiuse cream & Total bioburden after storage \\
\hline $\begin{array}{l}\text { Loss of pharmaceutical } \\
\text { elegance and patient } \\
\text { acceptability }\end{array}$ & $\begin{array}{l}\text { Speckling caused by the interaction of the } \\
\text { drug containing amine group with a minor } \\
\text { component in the lactose resulting in the } \\
\text { formation of a chromatophore }\end{array}$ & $\begin{array}{l}\text { Slight yellow or brown speckling on the } \\
\text { surface of tablet containing spray-dried } \\
\text { lactose }\end{array}$ & Visual Examination \\
\hline $\begin{array}{l}\text { Formation of toxic } \\
\text { degradation products }\end{array}$ & Degradation of the drug component & $\begin{array}{l}\text { Formation of epianhydrotetracycline from } \\
\text { tetracycline, } \\
\text { Protein drugs }\end{array}$ & $\begin{array}{l}\text { Amount of degradation products during } \\
\text { shelf life }\end{array}$ \\
\hline Loss of package integrity & $\begin{array}{l}\text { Change in package integrity during storage } \\
\text { or distribution }\end{array}$ & Plastic screw cap losing back-off-torque & Specific package integrity tests \\
\hline Reduction of label quality & $\begin{array}{l}\text { Deterioration of label with time and cause } \\
\text { the ink to run and thus adversely affect } \\
\text { legibility }\end{array}$ & $\begin{array}{l}\text { Plasticizer from plastic bottle migrates into } \\
\text { the label }\end{array}$ & Visual examination of the label \\
\hline $\begin{array}{l}\text { Modification of any factor } \\
\text { of functional relevance }\end{array}$ & $\begin{array}{l}\text { Time-dependent change of any functionally } \\
\text { relevant attribute of a drug product that } \\
\text { adversely affects safety, efficacy, or patient } \\
\text { acceptability or ease of use }\end{array}$ & Adhesion ageing of transdermal patches & Monitoring changes \\
\hline
\end{tabular}




\section{IMPORTANCE OF STABILITY TESTING}

The primary reason for stability testing is the concern for the well-being of the patient suffering from the disease for which the products is designed. Apart from degradation of the unstable product into toxic decomposition products, loss of activity up to a level of $85 \%$ of that claimed on the label may lead to failure of the therapy resulting in death e.g. nitroglycerine tablets for angina and cardiac arrest. Because of this concern, it has become a legal requirement to provide data for certain types of stability tests for the regulatory agencies before approval of a new product. Second important concern is to protect the reputation of the manufacturer by assuring that the product will retain fitness for use with respect to all functionally relevant attributes for as long as they are on the market. Other benefits of stability studies at the developmental stage or of the marketed products are to provide a database that may be of value in selection of adequate formulations, excipients and container closure systems for development of a new product, to determine shelf life and storage conditions for development of a new product, preparation of registration dossier, to substantiate the claimed shelf life for the registration dossier and to verify that no changes have been introduced in the formulation or manufacturing process that can adversely affect the stability of the product (Singh et al., 2000; Carstensen et al., 2000).

\section{STABILITY TESTING METHODS}

Stability testing is a routine procedure performed on drug substances and products and is employed at various stages of the product development. In early stages, accelerated stability testing (at relatively high temperatures and/or humidity) is used in order to determine the type of degradation products which may be found after long-term storage. Testing under less rigorous conditions i.e. those recommended for long-term shelf storage, at slightly elevated temperatures is used to determine a product's shelf life and expiration dates. The major aim of pharmaceutical stability testing is to provide reasonable assurance that the products will remain at an acceptable level of fitness/quality throughout the period during which they are in market place available for supply to the patients and will be fit for their consumption until the patient uses the last unit of the product (Kommanaboyina et al., 1999). Depending upon the aim and steps followed, stability testing procedures have been categorized into the following four types.

\section{Real-Time stability testing}

Real-time stability testing is normally performed for longer duration of the test period in order to allow significant product degradation under recommended storage conditions. The period of the test depends upon the stability of the product which should be long enough to indicate clearly that no measurable degradation occurs and must permit one to distinguish degradation from inter-assay variation. During the testing, data is collected at an appropriate frequency such that a trend analysis is able to distinguish instability from day-to-day ambiguity. The reliability of data interpretation can be increased by including a single batch of reference material for which stability characteristics have already been established. Stability of the reference material also includes the stability of reagents as well as consistency of the performance of the instrument to be used throughout the period of stability testing. However, system performance and control for drift and discontinuity resulting from changes in both reagents and instrumentation must be monitored (Anderson et al., 1991).

\section{Accelerated stability testing}

In accelerated stability testing, a product is stressed at several high (warmer than ambient) temperatures and the amount of heat input required to cause product failure is determined. This is done to subject the product to a condition that accelerates degradation. This information is then projected to predict shelf life or used to compare the relative stability of alternative formulations. This usually provides an early indication of the product shelf life and thus shortening the development schedule. In addition to temperature, stress conditions applied during accelerated stability testing are moisture, light, agitation, gravity, $\mathrm{pH}$ and package (Kommanaboyina et al., 1999). In accelerated stability testing the samples are subjected to stress, refrigerated after stressing, and then assayed simultaneously. Because the duration of the analysis is short, the likelihood of instability in the measurement system is reduced in comparison to the real-time stability testing. Further, in accelerated stability testing, comparison of the unstressed product with stressed material is made within the same assay and the stressed sample recovery is expressed as percent of unstressed sample recovery. For statistical reasons, the treatment in accelerated stability projections is recommended to be conducted at four different stress temperatures. However, for thermolabile and proteinaceous components, relatively accurate stability projections are obtained when denaturing stress temperatures are avoided (Anderson et al., 1991).

The concept of accelerated stability testing is based upon the Arrhenius equation (1) and modified Arrhenius equation (Anderson et al., 1991), (Connors et al., 1973) (2):

$$
\ln K=\ln A+\frac{\Delta E}{E \pi}
$$

where $K=$ degradation rate/s, $A=$ frequency factor/s, $\Delta E=$ activation energy $(\mathrm{kJ} / \mathrm{mol}), \mathrm{R}=$ universal gas constant $(0.00831$ $\mathrm{kJ} / \mathrm{mol}), T=$ absolute temperature $(\mathrm{K})$

$$
\log \left(\begin{array}{l}
k_{2} \\
k_{1}
\end{array}\right)=\underset{2.303 R}{-E_{a}}\left(\begin{array}{cc}
1 & 1 \\
T_{2} & T_{1}
\end{array}\right)
$$

where $k_{1}$ and $k_{2}$ are rate constants at temperatures $T_{1}$ and $T_{2}$ expressed in degree kelvins; $E_{a}$ is the activation energy; $\mathrm{R}$ is the gas constant.

These equations describe the relationship between storage temperatures and degradation rate. Using Arrhenius equation, projection of stability from the degradation rates observed at high temperatures for some degradation processes can be determined. When the activation energy is known, the degradation rate at low temperatures may be projected from those observed at "stress" temperatures (Connors et al., 1973; Lachman et al., 1976; Bott et al., 2007). The stress tests used in the current International 
Conference on Harmonization (ICH) guideline (e.g., 40\% for products to be stored at controlled room temperature) were developed from a model that assumes energy of activation of about $83 \mathrm{~kJ}$ per mole (Anderson et al., 1991).

A common practice of manufacturers in pharmaceutical industries was to utilize various shortcuts such as $Q$ rule and bracket tables for prediction of shelf life of the products but these methods are not official either in ICH or FDA. The $Q$ rule states that a product degradation rate decreases by a constant factor $Q_{10}$ when the storage temperature is decreased by $10^{\circ} \mathrm{C}$. The value of $Q_{10}$ is typically set at 2,3 or 4 because these correspond to reasonable activation energies. This model falsely assumes that the value of $\mathrm{Q}$ does not vary with temperature. The bracket table technique assumes that, for a given analyte, the activation energy is between two limits (e.g., between 10 and $20 \mathrm{kcal}$ ). As a result, a table may be constructed showing days of stress at various stress temperatures. The use of a 10 to $20 \mathrm{kcal}$ bracket table is reasonable because broad experience indicates that most analytes and reagents of interest in pharmaceutical and clinical laboratories have activation energies in this range (Kommanaboyina et al., 1999; Anderson et al., 1991).

\section{Retained sample stability testing}

This is a usual practice for every marketed product for which stability data are required. In this study, stability samples, for retained storage for at least one batch a year are selected. If the number of batches marketed exceeds 50, stability samples from two batches are recommended to be taken. At the time of first introduction of the product in the market, the stability samples of every batch may be taken, which may be decreased to only $2 \%$ to $5 \%$ of marketed batches at a later stage. In this study, the stability samples are tested at predetermined intervals i.e. if a product has shelf life of 5 years, it is conventional to test samples at 3, 6, 9, 12, $18,24,36,48$, and 60 months. This conventional method of obtaining stability data on retained storage samples is known as constant interval method (Kommanaboyina et al., 1999; Carstensen et al., 1993). Stability testing by evaluation of market samples is a modified method which involves taking samples already in the market place and evaluating stability attributes. This type of testing is inherently more realistic since it challenges the product not just in the idealized retained sample storage conditions, but also in the actual marketplace (Kommanaboyina et al., 1999).

\section{Cyclic temperature stress testing}

This is not a routine testing method for marketed products. In this method, cyclic temperature stress tests are designed on knowledge of the product so as to mimic likely conditions in market place storage. The period of cycle mostly considered is 24 hours since the diurnal rhythm on earth is 24 hour, which the marketed pharmaceuticals are most likely to experience during storage. The minimum and maximum temperatures for the cyclic stress testing is recommended to be selected on a productby-product basis and considering factors like recommended storage temperatures for the product and specific chemical and physical degradation properties of the products. It is also recommended that the test should normally have 20 cycles (Kommanaboyina et al., 1999; Carstensen et al., 2000).

\section{GUIDELINES FOR STABILITY TESTING}

To assure that optimally stable molecules and products are manufactured, distributed and given to the patients, the regulatory authorities in several countries have made provisions in the drug regulations for the submission of stability data by the manufacturers. Its basic purpose was to bring in uniformity in testing from manufacturer to manufacturer. These guidelines include basic issues related to stability, the stability data requirements for application dossier and the steps for their execution. Such guidelines were initially issued in 1980s. These were later harmonized (made uniform) in the International Conference on Harmonization (ICH) in order to overcome the bottleneck to market and register the products in other countries. The ICH was a consortium formed with inputs from both regulatory and industry from European commission, Japan and USA. The World Health Organization (WHO), in 1996, modified the guidelines because the ICH guidelines did not address the extreme climatic conditions found in many countries and it only covered new drug substances and products and not the already established products that were in circulation in the $\mathrm{WHO}$ umbrella countries. In June 1997, US FDA also issued a guidance document entitled 'Expiration dating of solid oral dosage form containing Iron. WHO, in 2004, also released guidelines for stability studies in global environment (WHO, 2004). ICH guidelines were also extended later for veterinary products. A technical monograph on stability testing of drug substances and products existing in India has also been released by India Drug Manufacturers Association (Singh et al., 2000). Further, different test condition and requirements have been given in the guidance documents for active pharmaceutical ingredients, drug products or formulations and excipients. The codes and titles covered under ICH guidance have been outlined in the Table 2 .

Table. 2: Codes and titles used in ICH Guidelines.

\begin{tabular}{ll}
\hline ICH Code & \multicolumn{1}{c}{ Guideline title } \\
\hline Q1A & $\begin{array}{l}\text { Stability testing of New Drug Substances and Products (Second } \\
\text { Revision) } \\
\text { Stability testing : Photostability testing of New Drug Substances } \\
\text { and Products }\end{array}$ \\
Q1C & $\begin{array}{l}\text { Stability testing of New Dosage Forms } \\
\text { Bracketing and Matrixing Designs for stability testing of Drug }\end{array}$ \\
Q1D & $\begin{array}{l}\text { Substances and Products } \\
\text { Evaluation of stability data }\end{array}$ \\
Q1E & $\begin{array}{l}\text { Stability data package for Registration Applications in Climatic } \\
\text { Q1F }\end{array}$ \\
Q5C & Stability testing of Biotechnological/Biological Products \\
\hline
\end{tabular}

(Singh et al., 2000)

Series of guidelines related to stability testing have also been issued by the Committee for Proprietary Medicinal Products (CPMP) under the European Agency for the Evaluation of Medicinal Products (EMEA) to assist those seeking marketing 
authorization for medicinal products in European Union. These are listed in Table 3.

\begin{tabular}{ll} 
Table. 3: CPMP Guidelines for Stability \\
\hline \multicolumn{1}{c}{ CPMP code } & \multicolumn{1}{c}{ Guideline title } \\
\hline CPMP/QWP/ & $\begin{array}{l}\text { Guideline on Stability Testing for Applications for Variations } \\
\text { to a Marketing Authorization }\end{array}$ \\
576/96 Rev. 1 & Guideline on Stability Testing for Active Substances and \\
CPMP/QWP/ & $\begin{array}{l}\text { Medicinal Products Manufactured in Climatic Zones III and } \\
\text { 6142/03 }\end{array}$ \\
IV to be marketed in the EU
\end{tabular}
(Singh et al., 2000; CPMP/QWP/122/02, 2003)

\section{CLIMATIC ZONES FOR STABILITY TESTING}

For the purpose of stability testing, the whole world has been divided into four zones (I - IV) depending upon the environmental conditions the pharmaceutical products are likely to be subjected to during their storage. These conditions have been derived on the basis of the mean annual temperature and relative humidity data in these regions. Based upon this data, long-term or real-time stability testing conditions and accelerated stability testing conditions have been derived. The standard climatic zones for use in pharmaceutical product stability studies have been presented in the Table 4. The break-up of the environmental conditions in each zone and also the derived long-term stability test storage conditions, as given by WHO have also been presented. The stability conditions have also been harmonized and adjusted to make them more practical for industry application and rugged for generalized application (Singh et al., 2000; ICH Q1A(R2), 2003).

Table. 4: ICH Climatic zones and long term stability conditions.

\begin{tabular}{|c|c|c|c|c|}
\hline $\begin{array}{l}\text { Climatic } \\
\text { Zone }\end{array}$ & $\begin{array}{l}\text { Climate/ } \\
\text { Definition }\end{array}$ & $\begin{array}{l}\text { Major } \\
\text { Countries } \\
\text { /Region }\end{array}$ & $\begin{array}{l}\text { MAT*/Mean } \\
\text { annual partial } \\
\text { water vapour } \\
\text { pressure }\end{array}$ & $\begin{array}{l}\text { Long-term } \\
\text { testing } \\
\text { conditions }\end{array}$ \\
\hline I & Temperate & $\begin{array}{l}\text { United } \\
\text { Kingdom } \\
\text { Northern } \\
\text { Europe } \\
\text { Russia } \\
\text { United states }\end{array}$ & $\leq 15^{\circ} \mathrm{C} / \leq 11 \mathrm{hPa}$ & $21^{\circ} \mathrm{C} / 45 \% \mathrm{RH}$ \\
\hline II & $\begin{array}{l}\text { Subtropical and } \\
\text { Mediterranean }\end{array}$ & $\begin{array}{l}\text { Japan } \\
\text { Southern } \\
\text { Europe }\end{array}$ & $\begin{array}{l}>15-22^{\circ} \mathrm{C} \\
/>11-18 \mathrm{hPa}\end{array}$ & $\begin{array}{l}25^{\circ} \mathrm{C} / 60 \% \mathrm{RH} \\
30^{\circ} \mathrm{C} / 35 \% \mathrm{RH}\end{array}$ \\
\hline III & Hot and Dry & $\begin{array}{l}\text { Iraq } \\
\text { India }\end{array}$ & $>22^{\circ} \mathrm{C} / \leq 15 \mathrm{hPa}$ & \\
\hline IVa & Hot and humid & $\begin{array}{l}\text { Iran } \\
\text { Egypt }\end{array}$ & $\mathrm{hPa}$ & $30^{\circ} \mathrm{C} / 65 \% \mathrm{RH}$ \\
\hline $\mathrm{IVb}$ & $\begin{array}{l}\text { Hot and very } \\
\text { humid }\end{array}$ & $\begin{array}{l}\text { Brazil } \\
\text { Singapore }\end{array}$ & $>22^{\circ} \mathrm{C} />27 \mathrm{hPa}$ & $30^{\circ} \mathrm{C} / 75 \% \mathrm{RH}$ \\
\hline
\end{tabular}

*MAT - Mean annual temperature measured in open air.

(Singh et al., 2000; ICH Q1A(R2), 2003; Grimm et al., 1998)

\section{PROTOCOL FOR STABILITY TESTING}

The protocol for stability testing is a pre-requisite for starting stability testing and is necessarily a written document that describes the key components of a regulated and well-controlled stability study. Because the testing condition is based on inherent stability of the compound, the type of dosage form and the proposed container-closure system, the protocol depends on the type of drug substance or the product. In addition, the protocol can depend on whether the drug is new or is already in the market (Ali et al., 2008; Cha et al., 2001). The protocol should also reflect the regions where the product is proposed to be marketed e.g. if the product is planned to be used in climatic zones I-III, IVa and IVb, the stability program must include all these zones (Cha et al., 2001). A well designed stability protocol should contain the following information.

\section{Batches}

Stability studies at developmental stages are generally carried out on a single batch while studies intended for registration of new product or unstable established product are done on first three production batches, while for stable and well-established batches, even two are allowed. If the initial data is not on a fullscale production batch, first three batches of drug product manufactured post-approval should be placed on long-term studies using the same protocol as in approved drug application. Data on laboratory scale batches obtained during development of pharmaceuticals are not accepted as primary stability data but constitute supportive information. In general, the selection of batches should constitute a random sample from the population of pilot or production batches (Singh et al., 2000).

\section{Containers and closures}

The testing is done on the product in immediate containers and closures proposed for marketing. The packaging materials include aluminium strip packs, blister packs, Alu-Alu packs, HDPE bottles etc. This may also include secondary packs, but not shippers. Products in all different types of containers/closures, whether meant for distribution or for physician and promotional samples, are to be tested separately. However, for bulk containers, testing in prototype containers is allowed, if it simulates the actual packaging (Singh et al., 2000).

\section{Orientation of storage of containers}

Samples of the solutions, dispersed systems and semi solid drug products for stability studies must be kept upright and positioned either inverted or on the side to allow for full interaction of the product with the container-closure. This orientation helps to determine whether the contact between the drug product or solvent and the closure results in the extraction of chemical substances from the closure components or adsorption of product components in to the container-closure (Ali et al., 2008). 


\section{Sampling time points}

Frequency of testing should be such that it is sufficient to establish the stability profile of the new drug substance. For products with a proposed shelf life of at least 12 months, the testing frequency at the long-term storage condition should be every 3 months over the first year, every 6 months over the second year and annually thereafter throughout the proposed shelf life expiration date. In the case of accelerated storage conditions, a minimum of three time points, including the initial and end points, for example, 0,3 , and 6 months is recommended. When testing at the intermediate storage condition is necessary as a result of significant change at the accelerated storage condition, a minimum of four test points, including the initial and final time points, is recommended, for example, $0,6,9$ and 12 months. The test schedule for stability testing of a new product has been presented in Table 5 (Cha et al., 2001).

Table. 5: Test Schedule for stability testing of new products.

\begin{tabular}{lll}
\hline Environment & \multicolumn{1}{c}{$\begin{array}{c}\text { Sampling Time } \\
\text { Points (months) }\end{array}$} & \multicolumn{1}{c}{ Method \& Climatic zone } \\
\hline $25^{\circ} \mathrm{C} / 60 \% \mathrm{RH}$ & $\begin{array}{l}3,6,9,12,18,24, \\
36\end{array}$ & Long term for zones I and IV \\
$30^{\circ} \mathrm{C} / 35 \% \mathrm{RH}$ & $\begin{array}{l}3,6,9,12,18,24, \\
36\end{array}$ & Long term for zones III \\
$30^{\circ} \mathrm{C} / 65 \% \mathrm{RH}$ & $3,6,9,12,18,24$, & $\begin{array}{l}\text { Long term for zone IVa, or } \\
\text { intermediate condition for zones I } \\
\text { and II } \\
36\end{array}$ \\
$30^{\circ} \mathrm{C} / 75 \% \mathrm{RH}$ & $3,6,9,12,18,24$, & $\begin{array}{l}\text { Long term for zone IVa, or } \\
\text { intermediate condition for zones I } \\
\text { and II } \\
\text { Accelerated condition for all zones }\end{array}$ \\
$40^{\circ} \mathrm{C} / 75 \% \mathrm{RH}$ & 3,6 &
\end{tabular}

(Cha et al., 2001)

In case the same product of different strengths, multiple sizes, etc is required to be tested, reduced stability testing plans can be worked out, which involves less number of test points. The reduced testing plans are based on bracketing and matrixing statistical designs. Bracketing is the design of a stability schedule such that only samples on the extremes of certain design factors, e.g., strength, package size, are tested at all time points as in a full design. On the other hand, matrixing involves testing of a subset of the total number of possible samples for all combinations at a specific time point. Subsequently, another subset of samples for all factor combinations is tested. The factors that can be matrixed include batches, strengths with identical formulation, container sizes, fill sizes, and intermediate time points (Singh et al., 2000; Cha et al., 2001).

\section{Sampling Plan}

Sampling plan for stability testing involves, planning for the number of samples to be charged to the stability chambers and sampling out of the charged batch so as to cover the entire study. The first step should be the development of the sampling time points followed by the number of samples needed to be drawn at each pull point for complete evaluation of all test parameters and finally adding up to get the total number of samples. For example there would be a requirement of about 100 tablets per pull out in a long term or accelerated stability studies including 10 each for assay, hardness and moisture determination, 6 each for dissolution and disintegration and 50 for friability. This multiplied by the total number of pull outs will give the total number of tablets required for a study. This is followed by the development of a sampling plan, which includes the selection of the containers representing the batch as a whole but in an unbiased manner. A stratification plan has been suggested whereby from a random starting point every $n^{\text {th }}$ container is taken from the filling or packaging line ( $n$ is chosen such that the sample is spread over the whole batch). (Singh et al., 2000)

\section{Test storage conditions}

The storage conditions to be selected are based upon the climatic zone in which the product is intended to be marketed or for which the product is proposed to be filed for regulatory approval. General recommendations on the storage conditions have been given by ICH, CPMP and WHO. The abridged/indicative ICH and WHO storage conditions for drug products have been given in Table 6.

Table. 6: Stability test storage conditions for drug products.

\begin{tabular}{lccc}
\hline $\begin{array}{c}\text { Intended } \\
\text { storage } \\
\text { condition }\end{array}$ & $\begin{array}{c}\text { Stability } \\
\text { Test } \\
\text { Method }\end{array}$ & $\begin{array}{c}\text { ICH Test } \\
\text { temperature and } \\
\text { humidity (Period in } \\
\text { months) }\end{array}$ & $\begin{array}{l}\text { WHO Test } \\
\text { temperature and } \\
\text { humidity (Period } \\
\text { in months) }\end{array}$ \\
\hline $\begin{array}{l}\text { Room } \\
\text { temperature }\end{array}$ & Long term & $25 \pm 2^{\circ} \mathrm{C} / 60 \pm 5 \% \mathrm{RH}$ & $25 \pm 2^{\circ} \mathrm{C} / 60 \pm 5 \%$ \\
& & $(12)$ & $\begin{array}{c}\mathrm{RH} \text { or } \\
30 \pm 2^{\circ} \mathrm{C} / 65 \pm 5 \%\end{array}$ \\
& Intermediate & $30 \pm 2^{\circ} \mathrm{C} / 65 \pm 5 \% \mathrm{RH}(6)$ & $30 \pm 2^{\circ} \mathrm{C} / 65 \pm 5 \%$ \\
& Accelerated & $40 \pm 2^{\circ} \mathrm{C} / 75 \pm 5 \% \mathrm{RH}(6)$ & $40 \pm 2^{\circ} \mathrm{C} / 75 \pm 5 \%$ \\
& & & $\mathrm{RH}(6)$ \\
& & & $5 \pm 3{ }^{\circ} \mathrm{C}$ \\
Refrigerated & Long term & $5^{\circ} \mathrm{C} / \mathrm{ambient}(12)$ & $25 \pm 2^{\circ} \mathrm{C} / 60 \pm 5 \%$ \\
& Accelerated & $25 \pm 2^{\circ} \mathrm{C} / 60 \pm 5 \% \mathrm{RH}(6)$ & $\mathrm{RH}$ or \\
& & & $30 \pm 2^{\circ} \mathrm{C} / 65 \pm 5 \%$ \\
& & & $\mathrm{RH}$ \\
Freezer & Long term & $-20^{\circ} \mathrm{C} / \mathrm{ambient}(12)$ & $-20^{\circ} \mathrm{C} \pm 5{ }^{\circ} \mathrm{C}$ \\
\hline
\end{tabular}

(Cha et al., 2001; ICH Q1 A(R2), 2003; WHO, 2004)

\section{Test parameters}

The stability test protocol should define the test parameters that would be used for evaluation of the stability samples. The tests that monitor the quality, purity, potency, and identity which could be expected to change upon storage are chosen as stability tests. Therefore appearance, assay, degradation products, microbiological testing, dissolution, and moisture are standard tests performed on stability test samples. Microbiological tests include sterility, preservative efficacy and microbial count as applicable e.g. for liquid injectable preparations. The batches used for stability study must meet all the testing requirements including heavy metals, residue on ignition, residual solvents etc. Some of these are required at the time of product release but not required to be repeated during stability testing (Cha et al., 2001). Other tests like enantiomeric purity, particle size and polymorphic form etc have also been discussed in ICH guidance Q6A. 


\section{Test methodology}

It is always recommended to follow the procedures given in the official compendia, as the results obtained using the official tests, in general find better acceptance. If alternate methods are used, they are required to be duly validated. However, the assay of the drug should be carried out using a stability-indicating method, established by carrying out stress tests on the drug under forced decomposition conditions. This method should be validated for specificity, accuracy, precision and linearity, in the range to whicha) the drug is expected to fall during stability studies. For the assay of degradation products, the validated method should also include the limits of detection/quantification. The methods reported in literature should be used after confirming reproducibility and carrying out minimal validation, say of linearity, range, etc. It is always recommended to prepare a standard test protocol (STP) for each test (Singh et al., 2000; Ali et al., 2008).

\section{Acceptance criteria}

All analytical methods are required to be validated before initiating the stability studies. Similarly, the acceptance criteria for the analytical results as well as that for the presence of degradation products should also be fixed beforehand. The acceptance criteria for each test in the stability study is fixed in the form of numerical limits for the results expressed in quantitative terms e.g., moisture pick-up, viscosity, particle size, assay, degradation products, etc. and pass or fail for qualitative tests e.g., odour, colour, appearance, cracking, microbial growth, etc. These acceptance criteria should also include individual and total upper limits for degradation products. ICH guideline $\mathrm{Q} 3 \mathrm{~B}(\mathrm{R} 2)$ related to impurities in new drug products addresses degradation products in new drug formulations. The degradation products of the active or interaction products from the active ingredients and excipients and/or active and container component should be reported, identified, and/or qualified when the proposed thresholds are exceeded. The reporting threshold of impurities is based upon the intended dose. If the maximum daily dose is less than or equal to $1 \mathrm{gm}$, the limit is $0.1 \%$ and if greater than 1 , the limit is $0.05 \%$. The identification threshold of impurities is between $1.0-0.1 \%$ for the maximum daily dose ranging between $1 \mathrm{mg}$ and 2gm (Singh et al., 2000; Cha et al., 2001).

\section{CONDUCT OF STABILITY STUDIES}

The stability study is conducted by keeping the drug substance or the product in their proposed final packs (e.g. Aluminium strip, blister pack, Alu-Alu pack, HDPE container etc.), or prototype containers in the case of bulk drugs, in sufficient numbers in the stability chambers set at appropriate storage conditions as per the protocol. The samples are then withdrawn, as per the stability protocol, at the prescribed sampling intervals and are then analyzed by a suitable method. The sampling should preferably be from unopened container. As far as possible the samples are placed for testing as soon as they have been prepared and analyzed without delay after they have been withdrawn. Delay in placing the samples and analysis of withdrawn samples is known to affect the results. However, if there is an unavoidable delay, then the samples are frozen until they are subjected to analysis. In order to minimize the effect of day-to-day variability on the results, the following two approaches are followed. Samples are drawn in replicate. One of the samples is tested and others are kept at temperatures sufficiently low to prevent further drug loss and then all the samples are subjected to analysis on the same day at the end of study (i.e after withdrawl of the last sample) (Ali et al., 2008).

Second approach is to freeze the initial samples till the expiration period and test them at appropriate times by using them as internal standards in the assays (Ali et al., 2008).

\section{PRESENTATION AND RECORDING OF STABILITY DATA}

Stability data is recorded in an organized, comprehensive and cumulative format. The stability data table is the means for reporting the results of the stability study in a concise format for ease of review and interpretation. The data is recorded in a proper tabular format and all-encompassing information on a batch is recorded at one place. Similar sheets are prepared for each batch. When, it is not possible to collect a sample exactly at the designed time (i.e., 3, 6, 9, 12 month, etc.), the sample may be withdrawn conveniently, and the actual time of collection should be indicated in the format sheet. The data can be grouped by storage condition and time interval to present the stability as a function of time for each environmental condition studied. Data can be presented in multiple tables taking care that it is easily interpretable. In addition, a graphical presentation of stability data versus time for the test data can be used to illustrate trends in data and may be helpful for data evaluation. A graphical presentation of the data, however, cannot replace the tabular presentation for a regulatory filing. The results of the statistical analysis, wherever appropriate and analysis of impurities should also be discussed. Details on the above are available in ICH Q3A and Q3B (Cha et al., 2001).

\section{MEAN KINETIC TEMPERATURE}

The Mean kinetic temperature is the single calculated temperature at which the total amount of degradation over a particular period is equal to the sum of the individual degradations that would occur at various cycles of higher and lower temperature. It is an isothermal storage temperature that simulates the non isothermal effects of storage temperature variation. The MKT takes into account seasonal and daily temperature variations during a year. It expresses the cumulative thermal stress undergone by a product at varying temperatures during storage and distribution. The concept of MKT is applied in order to provide assurance that the actual storage conditions will not affect adversely the stability and shelf life of the product. This is based upon the fact that the degradation rate constants are temperature dependent. A controlled room temperature maintained thermostatically to the usual working environment of $20^{\circ} \mathrm{C}$ to $25^{\circ} \mathrm{C}$ results in a mean kinetic temperature calculated to be not more than $25^{\circ} \mathrm{C}$. This concept is applied to pharmacies, hospitals, distribution and storage areas and vehicles and warehouses. Articles may be labeled for storage at "controlled 
room temperature" or at "up to $25^{\circ} \mathrm{C}$ ", or any other relevant word/phrase based on the same mean kinetic temperature. (Kommanaboyina et al., 1999), (Grimm et al., 1998), (Grimm et al., 1980), (USP 1995) The distribution of the countries and regions of the world into four different climatic zones has been on the basis of the mean kinetic temperature.

Mean kinetic temperature is calculated by two methods i.e. USP method and FDA method. In the USP method, MKT is calculated from the average storage temperatures recorded over a 1 -year period and the running average calculated from the average of weekly high and low temperatures recorded over the preceding 52 weeks. This results in entering 52 data points and calculation is done by Hayne's equation, which is derived from Arrhenius equation and relates degradation rate constants at different temperatures to the activation energy.

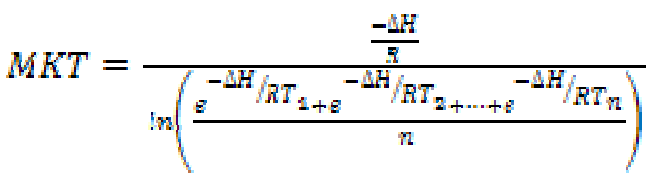

where $M K T$ is the mean kinetic temperature; $\Delta H$ is the energy of activation, in $\mathrm{kJ} / \mathrm{mol} ; R$ is the universal gas constant, $83.144 \mathrm{~kJ} / \mathrm{mol}$ $(5-240 \mathrm{~kJ} / \mathrm{mol}) ; T_{1}$ is the arithmetic mean of the highest and lowest temperatures recorded during the first time period (e.g., the first week); $T_{2}$ is the arithmetic mean of the highest and lowest temperatures recorded during the second time period (e.g., the second week); $T_{n}$ is the arithmetic mean of the highest and lowest temperatures recorded during the $n^{\text {th }}$ time period (e.g. $n^{\text {th }}$ week), $n$ being the total number of average storage temperatures recorded during the annual observation period; and all temperatures $T$ being absolute temperatures in degrees Kelvin (K) (Kommanaboyina et al., 1999).

The FDA recommends the method of entering both the individual highest and the lowest temperatures (rather than averages) in the equation for the calculation of MKT. This results in entering 104 data points, in contrast to USP's 52 points. If temperatures are electronically recorded at many times during a day and all the values are used in the calculation of MKT, then there is no difference between the USP and FDA method (Kommanaboyina et al., 1999).

\section{EXPIRATION DATE/SHELF LIFE}

An expiration date is defined as the time up to which the product will remain stable when stored under recommended storage conditions. Thus, an expiration date is the date beyond which it is predicted that the product may no longer retain fitness for use. If the product is not stored in accordance with the manufacturer's instructions, then the product may be expected to degrade more rapidly. Shelf life is the time during which the product, if stored appropriately as per the manufacturer's instructions, will retain fitness for use $(>90 \%$ of label claim of potency). The expiration date is also defined as the date placed on the container/labels of a drug product designating the time during which a batch of the product is expected to remain within the approved shelf life specifications, if stored under defined conditions and after which it should not be used (Kommanaboyina et al., 1999).

\section{Estimation of Shelf Life}

The shelf life is determined from the data obtained from the long term storage studies. The data is first linearized and test for goodness of fit is applied. The linearized data is then analyzed to see that the slope and the intercepts are matching. Table 7 gives the different possibilities in the pattern of the concentration-time data of the three batches. The data is pooled accordingly and used for estimation of the common slope (Singh et al., 2000; Singh et al., 1999).

Table. 7: Pattern of concentration-time data and pooling decision.

\begin{tabular}{cclccc}
\hline Slope & Intercept & \multicolumn{1}{c}{ Variation Factor } & Pooling \\
\hline Identical & Identical & Nil & Yes \\
Identical & Different & $\begin{array}{l}\text { Batch e.g. unequal initial drug } \\
\text { concentrations }\end{array}$ & No \\
Different & Identical & $\begin{array}{l}\text { Storage e.g. difference in the rate of drug } \\
\text { loss }\end{array}$ & No \\
Different & Different & $\begin{array}{l}\text { Interactive Forces-Both batch and storage } \\
\text { factor }\end{array}$ & No \\
\hline
\end{tabular}

For determination of significance of difference in case of slope or intercept, statistical tests like t-test should be applied. The data is available in the form of only five data points i.e. 0, 3, 6, 9 and 12 months, either pooled from the three batches or from the three individual batches if they are not fit for pooling. In case data is not fit for pooling, stability estimates are to be made on the worst batch. The shelf life/expiry date is determined from the regression line of this five point data based on calculation of $95 \%$ one-sided confidence limit. For reading the expiry date, 90\% drug concentration is considered as the lowest specification limit and the point where the extension line cuts the $95 \%$ confidence limit line is taken as an expiry date. Because shelf life derived from the intersection of the lower $90 \%$ confidence bound and $90 \%$ potency value has a $95 \%$ confidence level, therefore there is only a $5 \%$ chance that our estimate of the shelf life will be too high (Ali et al., 2008). For new drugs, it is a general practice to grant only two-year expiry initially, which is based on satisfactory one year long-term and 6 months accelerated stability data. The expiry date for third and later years is allowed only on production of real-time data for the subsequent years (Singh et al., 2000). Most pharmaceutical products are characterized by only one shelf life. However, in some cases a product may have two e.g. a freeze-dried (lyophilized) protein product may have only 1 shelf life, say 2 years, for the product stored in the dry condition and a $2^{\text {nd }}$ shelf life, say 2 days, for the product when it has been reconstituted with the appropriate vehicle and is ready for injection (Carstensen et al., 2000) .

\section{Conformance period}

The conformance period is determined from the intersection of the lowest (or highest) acceptable value of the stability parameter and the $95 \%$ confidence bound of the regression line. Shelf life assigned to a product is equal to, or less than, the 
conformance period and is usually a convenient rounded off number (e.g. 7 days, 1 month, 1 year, 18 months, or 2 , 3, or 5 years). e.g. if for 3 separate pharmaceutical products we obtained

conformance periods of 13.2, 26.1 and 39.4 months, we would probably assign shelf lives of 12,24 and 36 months to the 3 products. The difference between conformance period and the assigned shelf life is that conformance period provides an extra stability reserve (Carstensen et al., 2000).

\section{PHOTOSTABILITY TESTING}

USA FDA in 1996 issued ICH guidance for industry and stated that "the intrinsic photostability characteristics of new drug substances and products should be evaluated to demonstrate that, as appropriate, light exposure does not result in unacceptable change". In this photostability testing is recommended to be carried out on a single batch of material, however these studies should be repeated if certain variations and changes are made to the product (e.g., formulation, packaging). While D65 is the internationally recognized standard for outdoor daylight as defined in ISO 10977 (1993), ID65 is the equivalent indoor indirect daylight standard. Following this, testing of drugs in photostability chamber is now increasingly being followed as a standard procedure, especially for the products intended to be marketed in Asian countries (ICH Q1B, 1996; Singh et al., 2000).

\section{STABILITY TEST EQUIPMENT}

The equipment used for stability testing is called stability chamber. These are specialized environmental chambers that can simulate the storage condition and enable evaluation of product stability based on real-time, accelerated and long-term protocols. They are available in both walk-in and reach-in styles. Smaller chambers are preferred for accelerated testing, as the retention time of products is much less in these cabinets, while the walk-in chambers are preferred for long-term testing. Such chambers or rooms are engineered and qualified to ensure uniform exposure of the set conditions to all the samples in the chamber. These chambers are expected to be dependable and rugged because of the requirement of uninterrupted use for years. They are fitted with appropriate recording, safety and alarm devices. In addition, photostability chambers are also available and utilized both with and without temperature and humidity control. Two types of light sources are usually employed in photostability chambers, one is the combination of cool white and near UV fluorescent tubes, while second are the artificial daylight lamps, e.g., xenon or metal halide. It is required to obtain a total exposure of 1.2 millions lux hours. The visible light intensity is estimated using a lux meter. The calculation is made on how many hours of exposure is needed (Singh et al., 2000).

\section{OUT-OF-TREND RESULTS}

According to the ICH Q1A and WHO guidance results are considered out-of-trend (OOT) if the assay data is 5\% different from the initial data for the previous batch, because the results are significantly different. If OOT results are generated, a formal mechanism for investigating these results is rigorously followed, as defined by Barr decision. This procedure must have the ability to evaluate the data collection procedures and, in the case of an error, identify the root cause of the error, which might have caused the difference in results (Cha et al., 2001). The possible reasons for the same could be a) storage of different batches of products at different locations within the chamber, b) the batches are manufactured at different times and are charged to the chamber at whatever place available. It has been reported (Gaur et al., 2005) that despite that the temperature and humidity having been same at all the points within a chamber, the air velocity still varied at different locations, and this resulted in differential moisture pick up by a hygroscopic drug. Hence it is has been advised that stability testing chambers should be designed in a manner that air velocity also remains constant to the best possible within the test chambers (ICH Q1B, 1996).

\section{QUALITY BY DESIGN (QbD)}

Quality by design is a systematic approach to pharmaceutical product development that begins with pre-defined objectives and emphasizes product and process understanding and process control, based on sound science and quality risk management. It means designing and developing formulations and manufacturing processes to ensure a predefined quality. Thus, QbD requires an understanding of how formulation and process variables influence product quality. Relevant documents from the International Conference on Harmonization of Technical Requirements for Registration of Pharmaceuticals for Human Use (ICH), ICH Q8, Pharmaceutical Development, along with ICH Q9, Quality Risk Management, and ICH Q10, Pharmaceutical Quality Systems, indicate on an abstract level how quality by design acts to ensure drug product quality (Lionberger et al., 2008). QbD is a scientific, risk based, holistic, and proactive approach to pharmaceutical development. It is a deliberate design effort from product conception through commercialization. The goal of $\mathrm{QbD}$ is to fully understand how certain product attributes and process relate to the overall product performance. The potential advantage of the QbD approach to stability studies is to avoid conducting additional stability studies and filings when the scale, site, process, and route are altered from the initial registration stability batches. The barriers of this approach are related to cost, regulations, and guidelines.

\section{CURRENT TRENDS IN STABILITY TESTING}

Current trend, especially amongst the multinational pharmaceutical companies, is to define conditions for stability testing for global marketing. For this the companies are orienting their protocols to single set of conditions that covers extreme environmental conditions. The specific changes for global testing include increase in duration of accelerated testing period from 6 to 12 months, and conduct of additional tests at $50^{\circ} \mathrm{C} / 75 \% \mathrm{RH}$ for 3 months (Mischler et al., 2004). The concept behind this change is 
to avoid repetition of stability testing for other regions and efficient and optimum use of resources as all tests are done in one laboratory. Moreover testing under combination of three environmental factors, viz., temperature, humidity and light, has been reported to result in stronger deleterious effect on drug substances and products, than under temperature and humidity conditions only (Singh et al., 2002; Bhutani et al., 2003; Singh et al., 2003).

\section{CONCLUSION}

Stability testing is now the key procedural component in the pharmaceutical development program for a new drug as well as new formulation. Stability tests are carried out so that recommended storage conditions and shelf life can be included on the label to ensure that the medicine is safe and effective throughout its shelf life. Over a period of time and with increasing experience and attention, the regulatory requirements have been made increasingly stringent to achieve the above goal in all possible conditions to which the product might be subjected during its shelf life. Therefore, the stability tests should be carried out following proper scientific principles and after understanding of the current regulatory requirements and as per the climatic zone.

\section{REFERENCES}

Ali J., Khar RK., Ahuja A. Dosage form and design.3rd ed. Delhi. Birla Publications Pvt. Ltd ( 2008) 100-123

Anderson G., Scott M. Determination of product shelf life and activation energy for five drugs of abuse. Clin. Chem. 1991;37:398-402.

Bhutani H., Mariappan TT., Singh S. Behavior of Uptake of Moisture by Drugs and Excipients under Accelerated Conditions of Temperature and Humidity in the Absence and the Presence of light. Part 2. Packaged and Unpackaged anti-Tuberculosis drug products. Pharm. Technol. 2003;27:44-52

Bott RF., Oliveira WP. Storage conditions for stability testing of pharmaceuticals in hot and humid regions. Drug Dev. and Indus. Pharm. 2007;33:393-401.

Carstensen JT., Rhodes CT. Clin. Res. Drug Reg. Affairs. 1993;10:177-185

Carstensen JT. Drug Stability, Principles and Practices, Marcel Dekker, New York (2000)

Cha J., Gilmor T., Lane P., Ranweiler JS. Stability studies in Handbook of modern pharmaceutical analysis. Separation Science and Technology. Elsevier (2001) 459-505

Connors KA., Amidon GL., Kennon L. Chemical stability of pharmaceuticals-a handbook for pharmacists. New York: John Wiley \& Sons (1973) 8-119.

CPMP. Guideline on stability testing: Stability testing of existing active substances and related finished products. CPMP/QWP/122/02, 2003.
Gaur A., Mariappan TT., Bhutani H., Singh S. A Possible Reason for the Generation of Out-of-Trend Stability Results: Variable Air Velocity at Different Locations Within the Stability Chamber. Pharm. Technol. 2005;29:46-49.

Grimm W., Schepky G. Stabilitatsprufung in der Pharmazie, Theorie und Praxis, Editio Cantor Verlag, Aulendorf, 1980.

Grimm W. Extension of the international conference on harmonization tripartite guideline for stability testing of new drug substances and products to countries of climatic zones 3 and 4. Drug Dev. Ind. Pharm. 1998;24:313-325

ICH Q1A(R2). Stability testing guidelines : Stability testing of new drug substances and products. ICH Steering Committee, 2003.

ICH Q1B. Guidance for Industry: Photostability testing of new drug substances and products. CDER, US FDA, 1996

Kommanaboyina B., Rhodes CT. Trends in stability Testing , with Emphasis on Stability During Distribution and Storage. Drug Dev. Ind. Pharm. 1999;25:857-867.

Lachman L., DeLuca P. Kinetic principles and stability testing. The theory and practice of industrial pharmacy, $2^{\text {nd }}$ ed. Philadelphia. Lea and Febiger (1976) 32-89.

Lionberger AR., Lee LS., Lee L., Raw A., Yu XL. Quality by design : Concepts for ANDAs. The AAPS Journal. 2008;10:2.

Matthews RB. Regulatory Aspects of Stability Testing in Europe. Drug Dev. Ind. Pharm. 1999;25:831-856.

Mischler PG. Developing Stability Protocols for Global Product Registrations-An Update. Presentation at International Seminar on Stability Testing: Design and Interpretation for International Registration, 13 and 14 February 2002, IBC Life Sciences, London.

Singh S., Bakshi M. Guidance on conduct of stress test to determine inherent stability of drugs. Pharm Technol Asia, Special Issue, Sep./Oct. 2000;24-36.

Singh S, Bakshi M. Development of stability-indicating assay methods-A critical review. J. Pharm. Biomed. Anal. 2002;28:1011-1040.

Singh S., Bhutani H., Mariappan TT., Kaur H., Bajaj M., Pakhale SP. Behaviour of Uptake of Moisture by Drugs and Excipients under Accelerated Conditions of Temperature and Humidity in the Absence and the Presence of light. 1. Pure Anti-Tuberculosis Drugs and their Combinations. Int. J. Pharm. 2002;245:37-44

Singh S., Bhutani H., Mariappan TT., Kaur H., Bajaj M., Pakhale SP. Behaviour of Uptake of Moisture by Drugs and Excipients under Accelerated Conditions of Temperature and Humidity in the Absence and the Presence of light. 1. Pure Anti-Tuberculosis Drugs and their Combinations. Int. J. Pharm. 2002;245:37-44

Singh S. Drug Stability Testing and Shelf-life Determination According to International Guidelines. Pharm. Technol. 1999;23:68-88

Singh S. Stability testing during product development in Jain NK Pharmaceutical product development CBS publisher and distributors. India, (2000) 272-293.

U.S. Pharmacopoeial Convention, Inc., The United States Pharmacopoeia 23/National Formulary 18, Author, Rockville, MD,.(1995) 11, 1940-1941, 1959-1963.

WHO. Stability studies in a global environment. Geneva meeting working document QAS/05.146 with comments, (2004). 